\title{
Scif/0 Books
}

\section{Parte 1}

III - O centro agroambiental do Tocantins (CAT): concepções situacionais de desenvolvimento rural para a região de Marabá - PA

\section{Luciano Leal Almeida}

SciELO Books / SciELO Livros / SciELO Libros

ALMEIDA, LL. III - O centro angroambiental do Tocantins (CAT): concepções situacionais de desenvolvimento rural para a região de Marabá - PA. In: NEVES, DP., GOMES, RA., and LEAL, PF., orgs. Quadros e programas institucionais em políticas públicas [online]. Campina Grande: EDUEPB, 2014, pp. 79-104. ISBN. Available from SciELO Books $<$ http://books.scielo.org $>$.

\section{(c) (1)(2)(2)}

All the contents of this chapter, except where otherwise noted, is licensed under a Creative Commons Attribution-Non Commercial-ShareAlike 3.0 Unported.

Todo o conteúdo deste capítulo, exceto quando houver ressalva, é publicado sob a licença Creative Commons Atribuição - Uso Não Comercial - Partilha nos Mesmos Termos 3.0 Não adaptada.

Todo el contenido de este capítulo, excepto donde se indique lo contrario, está bajo licencia de la licencia Creative Commons Reconocimento-NoComercial-CompartirIgual 3.0 Unported. 


\title{
III
}

\section{Centro Agroambiental do Tocantins (CAT): concepções situacionais de desenvolvimento rural para a região de Marabá - $P A$}

\author{
Luciano Leal Almeida ${ }^{18}$
}

O Centro Agroambiental do Tocantins (CAT) foi fundado em 1988, como produto de ações institucionais em parceria, envolvendo pesquisadores ligados à Universidade Federal do Pará (UFPA), pesquisadores franceses ligados ao Groupe de Recherche et d'Échanges Technologiques (GRET) ${ }^{19}$ e um grupo de sindicalistas que atuavam na região de Marabá, sudeste do Pará $^{20}$. O programa de

18 Engenheiro Agrônomo formado pela Universidade Federal Rural do Rio de Janeiro (UFRRJ) e Mestre pelo Programa de Pós-Graduação de Ciências Sociais em Desenvolvimento, Agricultura e Sociedade (CPDA)/UFRRJ. Trabalhou com pesquisas durante a graduação e no mestrado na área de formação de quadros institucionais, sindicalismo rural e relações de mediação/poder na região sudeste do Pará. Atualmente trabalha como indigenista na Fundação Nacional do Índio (FUNAI) em Tucumã-PA. Email: llaleal@yahoo.com.br .

19 É uma associação não governamental, criada em 1970, de apoio à cooperação internacional, à solidariedade profissional e redução da pobreza nos países da Ásia, África, Europa e América Latina.

200 que denomino neste trabalho como "região de Marabá" abrange os municípios de Marabá, Itupiranga, Jacundá, Nova Ipixuna, São João do Araguaia e São Domingos do Araguaia, raio de atuação do Laboratório Sócio-Agronômico do Tocantins/LASAT. Trata-se, pois, de uma denominação fundada na área de atuação de determinadas forças sociais e políticas e não por critérios geográficos. 
ação fundamentado pela criação do CAT projetava, como um dos objetivos, permitir a estabilização da agricultura familiar e consolidar um novo campesinato na fronteira amazônica, buscando também contribuir na discussão da conservação ambiental e uso racional dos recursos naturais. Portanto, prefigurava ações institucionalizadas de mediação entre agricultores organizados por representação política delegada e intercâmbio com porta-vozes de outras instituições, no caso e principalmente, órgãos estatais, inclusive grupos de pesquisa universitários, também associados por parceria com instituições francesas também voltadas para construção sistematizada de conhecimentos entre agricultores.

Partindo do princípio de que as relações de mediação criam vínculos ambíguos, posto que envolvem reciprocidade e dominação, neste artigo apresento alguns dos resultados da pesquisa que realizei sobre a relação estabelecida entre os professores -pesquisadores da UFPA e os porta-vozes do movimento sindical de trabalhadores rurais situados na região de Marabá, diante da criação de um quadro institucional complexo, a partir do final da década de 1980. Procuro entender os significados elaborados por essa mediação institucional e acadêmica no processo de construção de campos de profissionalização dos trabalhadores rurais. Acompanhando compreensivamente esses processos, atribuo a devida atenção à emergência de conflitos e à construção de assimetrias de poder inerentes a essas relações. Por fim, dedico atenção ao estudo das condições em que tais ações assim institucionalizadas influenciaram o desenvolvimento da agricultura familiar na região de Marabá. Para efeitos de contribuição ao conjunto de questões eleitas para a reflexão sobre modos de aplicação de políticas públicas, enfatizo a importância da produção institucional de ideias e valores, bem como a formação de agentes encarregados da difusão

Optei por utilizá-la porque ela possui legitimidade entre os atores locais e sua delimitação espacial se articula com as dinâmicas territoriais que se sucedem nessa porção do estado. Essa região praticamente coincide com a delimitação proposta pela Secretaria de Desenvolvimento Territorial do Ministério do Desenvolvimento Agrário (SDT/MDA) para o território do Sudeste do Pará. 
e reprodução desse mesmo ideário, voltado para projeção de referências de reordenação da vida social e das relações entre grupos, classes e porta-vozes do Estado.

Para entender as ações dos diferentes agentes sociais ao longo do período em que aquele processo teve curso, atribuo atenção ao estudo dos fatos históricos relevantes no período e que foram intervenientes nas ações para constituição dos quadros institucionais. Para tanto, adoto o seguinte procedimento: 1 ) analiso o conjunto de registros impressos, confeccionados pelos diferentes agentes sociais como atas de reuniões, relatórios e ofícios referentes ao Programa; 2) estimulo, por entrevista, a produção de memória recente dos envolvidos nos processos, incorporando 21 interlocutores: pesquisadores, sindicalistas e agricultores que, em diferentes momentos, participaram da construção do CAT.

\section{A Constituição Social do CAT}

O surgimento do Programa CAT se insere no contexto específico de expressão de conflitualidades inerentes à construção da fronteira amazônica no decorrer dos anos de 1970 e 1980, tempo em que melhor se configuraram as expectativas e lutas sociais pela posse da terra na região sudeste do Pará. Essa transformação pautou-se em processos complexos, envolvendo um conjunto de agentes sociais que disputavam o acesso a recursos materiais que dessem conta de projetos de mobilidade e reprodução social como agricultores. A possibilidade de acumular riqueza com a exploração dos recursos materiais e a ausência de um suposto domínio particular sobre as terras estimularam a ocupação do espaço regional; e influenciaram a migração de pessoas de várias partes do país, em especial do Nordeste, em diferentes condições socioeconômicas. Formou-se inicialmente uma economia com base no extrativismo, que influenciou o ritmo de boa parte dos acontecimentos sociais, econômicos e políticos nas décadas seguintes (HÉBETTE, 2004d; ASSIS, 2007).

Até a década de 1970, não existia organização camponesa institucionalizada e a agricultura tinha um papel econômico muito 
secundário no quadro regional, com exceção do arroz e da criação de gado, visto que essas atividades operavam com cadeias de comercialização mais consistentes. A atividade produtiva sobre a qual havia se estruturado a sociedade, ao longo dos séculos, e que sustentava a economia, era o extrativismo nas suas diversas expressões (látex, castanha, caça de animais silvestres e mineração). Os trabalhadores viviam na dependência de patrões e de oligarquias locais. Não havia, por conseguinte, espaço para a organização política formal por esses trabalhadores.

Durante as décadas de 1970 e 1980, a fisionomia econômica e social da região se transformou radicalmente. A mudança se iniciou ainda na década de 1960, quando pequenos agricultores oriundos do Maranhão penetraram nessa região pelo município de São João do Araguaia, mas, dessa vez, não mais apenas para trabalhar nos castanhais e no garimpo, mas para ocuparem "terras livres" ${ }^{21}$, e se sedentarizarem com a formação de lavouras (VELHO, 1974). Essa mudança se acelerou e ampliou fortemente com a abertura oficial da fronteira amazônica durante o regime militar, que decidiu, em 1970, implantar a rodovia Transamazônica e ampliar a infraestrutura regional (hidrelétricas, rodovias, etc.), atraindo migrantes de diversas partes do país.

Segundo Hébette (1996a), a abertura da fronteira amazônica carregou consigo a marca do regime autoritário que a estimulou. A violência que geralmente costuma acompanhar a penetração organizada em "novos territórios" foi reforçada pela violência dos órgãos de repressão instituídos pelo regime militar (Grupo Executivo de Terras do Araguaia-Tocantins/GETAT e o Conselho Nacional de Segurança/CNS) ${ }^{22}$. Para o autor, o reconhecimento desse quadro institucional é fundamental para a compreensão dos

21 Concepção que não levava em conta a apropriação dessas terras por povos indígenas.

22 O GETAT foi criado em 1980, seu principal objetivo era suavizar os conflitos agrários na região por meio da ordenação da ocupação. A sua área de atuação correspondeu a região denominada "Bico do Papagaio (ASSIS, 2007). 
processos sociais que vieram paralelamente, em consequência, ocorrer na região de Marabá.

Foi também no bojo desse processo de colonização oficial e/ou espontânea que os posseiros começaram sua organização política. $\mathrm{Na}$ ausência de um órgão legitimamente representativo de seus interesses, os trabalhadores rurais tiveram que investir na criação de suas próprias estratégias de defesa de direito a terra, calcadas em estratégias familiares e de parentesco, de conterraneidade e vizinhança (HÉBETTE, 1996a). Essas estratégias, entretecidas em plano comunitário, forneceram as bases para a constituição das Comunidades Eclesiais de Base (CEBs), estimuladas, nos anos 1970, por religiosos adeptos da Teologia da Libertação, investimento organizativo que recuperou, num nível político mais elaborado e mais consistente, a inspiração dos movimentos de esquerda e a sensibilidade do clero progressista originário da Ação Católica ${ }^{23}$.

Nesse mesmo período, pesquisadores do Núcleo de Altos Estudos Amazônicos (NAEA) ${ }^{24}$ da Universidade Federal do Pará, que também atuavam como assessores desses movimentos organizativos começaram a construir os primeiros contatos com esses migrantes, em sintonia com aqueles espaços de formação organizados por religiosos locais.

Essa luta dos migrantes pela terra constitui-se como campo de encontro de todos os agentes sociais - clero, militantes sociais e políticos, advogados, pesquisadores e estudantes - que lutavam contra o regime militar e a favor dos posseiros. Muitos deles encontravam em organizações das Igrejas Católica e Luterana e, em particular,

23 A Ação Católica Brasileira (ACB) foi um movimento controlado pela hierarquia da Igreja e fundado pelo Cardeal Dom Sebastião Leme e pelo Padre João Batista Portocarrero Costa em 1932. Tinha como um dos objetivos formar leigos para colaborar com a missão social da Igreja e propiciar a presença atuante do leigo católico na vida pública e social do país. Ela se organizou em vários ramos ou grupos como a Juventude Feminina Católica (JFC).

24 O NAEA surgiu dentro da UFPA com a reforma universitária de 1971, funcionando como um órgão de integração dentro da universidade para fomentar a pesquisa e a extensão, voltada, naquela época, por uma série de razões, para a área das Ciências Humanas. 
na Comissão Pastoral da Terra (CPT), um espaço institucional com certa "imunidade simbólica" à repressão. É nesse campo de forças muito diversificadas e, de certa forma, contraditórias - onde a vida política, sindical e religiosa estive tão imbricada em medida e formas diferentes - que os trabalhadores encontraram e constituíram seus primeiros mediadores sociais ${ }^{25}$ (NEVES, 2008).

É, portanto, nesse complexo campo de lutas e resistências que também surgiram as lideranças camponesas que, ao final da década de 1970, foram peças fundamentais na criação dos Sindicatos de Trabalhadores Rurais (STRs); ou, por tais condições sociais e políticas, vieram a conquistá-los, deslocando-os das mãos de dirigentes instalados pelo Instituto Nacional de Colonização e Reforma Agrária (INCRA). Em outros casos ainda, tais sindicatos foram criados, permitindo ampliar a rede institucional de apoio à organização política em construção. Portanto, foi por via do sindicalismo que as lideranças iniciaram sua luta por maior autonomia e começaram a elaborar um projeto coletivo em nível regional de organização da representação política. Aquelas instituições puderam contar ainda com outros apoios como da CPT, muito participativa e dinâmica, também com o apoio do Movimento de Educação de Base (MEB), pesquisadores engajados no estudo e assessoramento dos desdobramentos desses processos; e entidades como a Federação de Órgãos para Assistência Social e Educacional (FASE), Centro de Estudos e Pesquisa e Assessoria Sindical e Popular (CEPASP) e a Sociedade Paraense de Defesa dos Direitos Humanos (SPDDH).

A atuação dessas lideranças nos conflitos por terra que ocorreram, nas décadas de 1980 e 1990, consolidou as entidades sindicais

25 Estamos considerando que os pesquisadores por meio do papel que exercem no CAT e na UFPA atuam como mediadores, bem como os sindicalistas. Os pesquisadores atuariam como elos importantes na estruturação e nas relações de mediação entre esses sindicalistas e outros agentes externos; já os sindicalistas seriam chamados para agirem como elos importantes na estruturação das relações entre agricultores e pesquisadores dentro do CAT. No entanto, estamos considerando que pesquisadores e sindicalistas interagem em múltiplas direções. É de grande relevância, por exemplo, a relação que estabelecem com outros mediadores de outras entidades de apoio e de outras organizações localizados dentro e fora do contexto da região de Marabá. 
como legítimas representantes dos interesses da maioria dos camponeses e trabalhadores rurais na região de Marabá.

De acordo com Hébette (1991), os pesquisadores da UFPA que acompanhavam a dinâmica de ocupação da região eram frequentemente indagados pelos posseiros quanto a seus múltiplos problemas, sem que aqueles pudessem oferecer respostas. Era o caso, por exemplo, dos questionamentos técnicos demandados pelo desejo dos agricultores de incorporarem novas produções, principalmente destinadas ao mercado, isto é, que pudessem complementar as culturas temporárias tradicionais.

Nesse sentido, a forma de uso da terra tinha sido, desde a década de 1980, uma das preocupações dos pequenos agricultores do Pará e de suas assessorias. A resposta a essa preocupação veio a proporcionar o surgimento de novas organizações e de projetos orientados no sentido de soluções especificamente técnicas e econômicas aos problemas. Portanto, voltadas diretamente para a questão da produção e das trocas comerciais.

Esse aspecto foi ressaltado por Leroy (2000), ao apontar que o CAT se insere, em âmbito nacional e regional, num movimento ascendente, embora pouco valorizado, de organização e comercialização da produção. A preocupação, nessa época, era a de empreender políticas duradouras que respondessem estrategicamente às necessidades básicas da categoria socioeconômica, como a implementação e a viabilidade da pequena produção, comercialização e emprego de novas tecnologias.

Assim, o modo como o Programa CAT se estruturou vai refletir o debate que "começou a se dar na época sobre a relação entre o econômico e o político no sindicalismo rural" (Ibidem, 21), pois começavam a emergir os problemas então chamados de "econômicos" da produção e da comercialização agrícola, ao mesmo tempo em que havia a conquista da terra.

Outro aspecto relacionado ao surgimento do Programa CAT diz respeito ao contexto de abertura política que foi se configurando a partir de 1985. Naquele período, a democratização do país permitiu maior abertura e visibilidade a possíveis apoios de cooperação internacional entre a pequena produção agrícola e a pesquisa científica, aproximações que iriam resultar em projetos com ênfase no 
desenvolvimento rural e sustentável em diversas regiões do país. É nesse contexto de apoio externo que o CAT foi gestado, ou seja, por um convênio formulado no quadro da cooperação franco-brasileira. Convém ainda mencionar que a agricultura familiar francesa vinha sendo considerada uma referência para os pesquisadores e planejadores brasileiros e franceses que estavam envolvidos nesse projeto. Esta referência havia justificado, em outubro de 1986, um convênio complementar ao Acordo Geral de Cooperação Científica e Técnica de janeiro de 1967, firmado entre Brasil e França, desta vez, especificamente para a pequena agricultura.

Diante desse contexto, pesquisadores do NAEA e sindicalistas dos municípios de Itupiranga, Marabá, Jacundá e São João do Araguaia, legitimados pelos seus percursos de lutas, consolidaram uma parceria institucional entre esses STRs e a UFPA, no âmbito da cooperação franco-brasileira. Para a efetivação dessa parceria, tais atores contaram, ainda, com a participação fundamental de pesquisadores da Universidade das Antilhas e das Guianas, que já tinham experiências em projetos de cooperação na região do Caribe.

Dessa forma, o Programa CAT surge a partir de demanda que encontra interlocutores, ou seja, pesquisadores sensíveis às demandas das organizações sindicais que, como advogavam, sem abrir mão dos rigores da ciência, iriam atuar como mediadores, visando a propiciar consistência a um projeto de desenvolvimento regional em que os pequenos agricultores estivessem contemplados. Nessa perspectiva, é importante ressaltar também que a demanda desses agricultores da região de Marabá era entendida como algo legítimo por esses pesquisadores, e que todo o processo de construção do Programa se daria a partir do diálogo com os sindicalistas.

Evidências empíricas apontaram a destacada e fundamental contribuição de Jean Hébette na consolidação do CAT, devido, em grande parte, ao seu capital simbólico (de prestígio), ${ }^{26}$ adquirido por sua participação como assessor e pesquisador, em vários anos de pesquisa nessa região. Entretanto, outros agentes (sindicalistas e pesquisadores) tiveram também um papel fundamental na cons-

26 No sentido proposto por Pierre Bourdieu (1989). 
trução de uma rede institucional de viabilização e consolidação da proposta.

Para entender melhor esse processo, as relações de confiança entre pesquisadores, assessores e sindicalistas são elementos importantes, tal como analisei durante a pesquisa. Num primeiro momento, esta confiança estava depositada em algum integrante dessa rede de relações que, por sua vez, iria propiciar as bases para a construção da confiança num terceiro. Da mesma forma, esse processo não se dá sem que haja relações de poder. Isto significa que o estabelecimento da confiança se deu a partir da conjunção de diversos elementos (simbólicos e/ou materiais), a partir dos quais emergiu e se estabeleceu a relação. Ou seja, não fora qualquer agente que desempenhara uma suficiente influência sobre outros, de forma a produzir um efeito de confiança. Nesse sentido, acredito que os atributos de figura de padre/assessor que Jean Hébette carregava, influenciaram as relações de confiança entre agricultores e pesquisadores. Devido ao contexto no qual se dá tal relação, um ambiente rural onde historicamente os agricultores desenvolveram uma acentuada religiosidade e onde entidades da Igreja Católica estiveram atuando intensamente, é verificável a grandeza do poder simbólico da figura de um padre. Portanto, falar de confiança requer uma análise das relações que a geram e, portanto, situá-las histórica e relacionalmente em determinado contexto.

Bourdieu (1989) observa também que, para tentar entender essa força de mobilização que as lideranças possuem, quer a título pessoal, por delegação ou como mandatário de uma organização (partido ou sindicato) detentora de um capital político acumulado no decurso das lutas passadas, é necessário levar em consideração o capital pessoal de notoriedade e de popularidade - firmado no fato de ser conhecido e reconhecido numa pessoa (de ter um nome, uma reputação etc.) e também no fato de possuir certo número de qualidades específicas que são a condição de aquisição e da conservação de uma boa reputação - que cada militante possui, e no qual é:

Frequentemente produto da reconversão de um capital de notoriedade acumulado em outros domínios e, em particular, em profissões 
que, como as profissões liberais, permite tempo livre e supõe um certo capital cultural ou, como no caso dos advogados, um domínio profissional da eloqüência (BOURDIEU, 1989, p.191).

Dessa forma, ao pensarmos na atuação das lideranças ou mediadores sociais como Jean Hébette, é necessário levar em consideração esse "capital de notoriedade acumulado em outros domínios", visto que as diferentes profissões permitem maior ou menor tempo livre destinado às atividades de militância. Também é preciso pensar no acúmulo de determinado capital cultural que está implícito no exercício de algumas profissões, como o hábito de leitura diária, domínio da fala e demais instrumentos que estão diretamente relacionados, principalmente, a profissões como a de pesquisador e padre (que é treinado para ouvir e aconselhar).

Outro aspecto que ainda abordei na pesquisa, enfatiza a abertura da UFPA, por meio do NAEA e desses mediadores institucionais, para a participação em organizações sindicais na definição de um projeto de pesquisa-desenvolvimento para a região de Marabá; e isto sem cair no equívoco de considerá-la como fruto de benevolência dessa instituição (ou desses pesquisadores); ou mesmo do acaso. Essa abertura e essa flexibilidade de funções têm ainda por base o acúmulo de experiências vividas ao longo das trajetórias desses sindicalistas na região de Marabá, que sinalizaram para os pesquisadores do NAEA, a possibilidade de partilhar com as organizações de trabalhadores rurais, uma parcela de responsabilidade da pesquisa e de ações de desenvolvimento rural.

Essa abertura é bastante significativa porque a relação entre sindicalistas e/ou agricultores e pesquisadores e/ou agentes de assistência técnica tinha, em muitos casos, (e ainda continua a ter) um caráter persuasivo, tendo em vista acelerar a adoção de tecnologia ou a busca de alternativas que pudessem contribuir para o desenvolvimento da agricultura familiar, sem, no entanto, criar um espaço de participação crítica dos próprios beneficiários desses projetos, ou seja, do agricultor e de sua família.

Segundo Henchen (2002), era comum considerar o destinatário dos projetos de desenvolvimento como audiência ou como clientela. 
Enfim, uma estrutura de massa amorfa, constituída por uma agregação de indivíduos que, enquanto membros de um determinado grupo, são substancialmente iguais ou igualizáveis, não diferenciáveis, mesmo se pertencentes a ambientes distintos, heterogêneos, com características socioculturais variadas. Nesse sentido, para o autor, era essa visão acerca dos destinatários dos projetos de pesquisa e desenvolvimento rural que contribuía "para o fracasso da maioria dos projetos colocados em prática, porque estes tinham por base uma perspectiva que ignorava o ponto de vista do trabalhador rural sobre as relações nas quais este estava inserido" (HENCHEN, 2002, p. 20).

Ao comentar questões relacionadas às varias percepções sobre o campesinato, Martins (1995, p.17) destacou a importância de ouvir; porém, advertia: deve-se perceber que:

Ouvir o campesinato não quer dizer, simplesmente, partir do próprio discurso dos agentes sociais [...] é preciso mobilizar recursos teóricos que permitam decifrar a fala do camponês, especialmente a fala coletiva do gesto, da ação, da luta camponesa; precisa-se "captar o sentido da fala, ao invés de imputar-lhe sentido, ao invés de desdenhá-la" ( MARTINS, 1995, p.17, grifo do autor).

Por certo, essas questões levantadas pelo autor convergiam ou eram partes da reflexão dos pesquisadores do NAEA/UFPA, quando estes se propuseram a construir uma parceria com sindicatos de trabalhadores rurais.

Por fim, é preciso esclarecer que essa parceria parece surgir como resultado de interrogações dos atores sociais ${ }^{27}$ que se propõem, em um determinado momento de suas trajetórias, modi-

27 Otor social não é aquele que age em conformidade com o lugar que ocupa na organização social, na sociedade, mas aquele que, através de suas ações, modifica o meio ambiente material e, sobretudo, social no qual está inserido; modificando a divisão do trabalho, as relações de dominação e mesmo as orientações culturais (TOURAINE, 1994, p.220). 
ficando o curso de relações anteriormente estabelecidas, sinalizar para a perspectiva de reconstruí-las em outras bases, em outros princípios. Dessa forma, haveria a possibilidade de surgirem relações democráticas e de alteridade entre parceiros/atores que se propunham a construir um projeto em conjunto, onde o diálogo permanente, assim se acreditava, seria da maior importância. Desta maneira, tentava-se evitar a repetição de velhos vícios tão presentes entre instituições ou entre indivíduos vinculados à extensão rural, relações que, em geral, estão assentadas em bases clientelistas, paternalistas, assistencialistas e, consequentemente, autoritárias.

Nesse sentido, se a construção ou a efetivação do Programa CAT podem ser consideradas como construção de um espaço socia ${ }^{28}$ que reunia agentes sociais com trajetórias historicamente distintas, é porque, no percurso dessas trajetórias, esses agentes perceberamse e foram percebidos, tanto dentro como fora de seus respectivos campos de ação, de sua área de atuação, como portadores de certa distinção, que lhes proporcionava visibilidade política e social, mas também certa convergência de objetivos e projeções.

A visibilidade e, de certa forma, a especificidade dessas ações são elementos chave que proporcionavam o reconhecimento de atores sociais históricos e sinalizam para o fato de que estes se encontram na condição de delegados, isto é, de alguém que dispõe de certa autorização social que lhes permite a negociação construtiva de um Programa, no qual estivessem envolvidas atividades de pesquisa, formação e ações de desenvolvimento, não mais em situação subalterna, mas agora, na condição de parceiros.

28 A noção de espaço social, conforme afirma Pierre Bourdieu: "Contém, em si, o princípio de uma apreensão relacional do mundo social: ela afirma, de fato, que toda "realidade" que designa reside na exterioridade mútua dos elementos que a compõem. Os seres aparentes, diretamente visíveis, quer se trate de indivíduos quer de grupos, existem e subsistem na e pela diferença, isto é, enquanto ocupam posições relativas a um espaço de relações que, ainda que invisível e sempre difícil de expressar empiricamente, é a realidade mais real (...) e o princípio real dos comportamentos dos indivíduos e dos grupos" (BOURDIEU, 1996, 46). 
Assim sendo, as lideranças dos sindicatos representados no CAT, com base em suas experiências de luta, nos seus enfrentamentos e/ ou negociações com o Estado, acreditava-se credenciadas, isto é, possuidoras de uma espécie de delegação ${ }^{29}$, que, de certa forma, as autorizava a falar em nome dos sindicatos, das delegacias sindicais, ou, de um modo geral, em nome dos pequenos agricultores e posseiros daquela região. Essa delegação, por certo, fora constituída enquanto resultado das trajetórias de luta, o que, portanto, lhe conferia legitimidade de ir ao encontro dos pesquisadores do NAEA, que já atuavam na região de Marabá, há algum tempo, desde meados da década de 1970 .

\section{Estrutura e ações do Programa CAT}

Alguns princípios consensuais orientaram a montagem do Programa CAT. Pretendia-se uma parceria baseada no diálogo entre lavradores, pesquisadores e técnicos. De acordo com Hébette \& Navegantes (2000), os princípios da parceria foram:

1) Uma parceria entre lavradores e instituições de pesquisa e ensino que passasse por uma organização representativa de trabalhadores rurais, mais especificamente dos STRs, legitimados por seu apoio à luta dos posseiros.

2) A importância da pesquisa agronômica e social permanente associada à organização camponesa para identificar sistematicamente as necessidades dos trabalhadores rurais e propor respostas.

3) A escolha de uma escala regional que oferecesse ao projeto a possibilidade de um impacto na área coberta pelos quatro

29 De acordo com Bourdieu (1989), o homem que possui capital político retira sua força política da confiança que o grupo põe nele. Ele retira o seu poder propriamente mágico sobre o grupo da fé na representação que ele dá ao grupo e que é uma representação do próprio grupo e da relação com os outros grupos. Mandatário unido aos seus mandantes por uma espécie de contrato racional - o programa -, ele é também campeão, unido por uma relação mágica de identificação àqueles que, como se diz, põem nele todas as esperanças (BOURDIEU, 1989). 
STRs com os quais já se tinha experiência de trabalho: os de Itupiranga, Jacundá, Marabá e São João do Araguaia, abrangendo uma área, na época, de cerca de $35.000 \mathrm{Km}^{2}{ }^{30}$

4) Ação que atingisse a mais ampla base camponesa, tentando levá-la adiante em conjunto, com objetivo de evitar a formação de segmentos privilegiados dentro de cada categoria.

5) Um horizonte temporal amplo, de esforço de desenvolvimento, calculado como equivalente a uma geração, para alcançar resultados satisfatórios e duráveis.

6) A implantação de um centro de encontros e reuniões que pudesse propiciar intercâmbios frequentes entre trabalhadores rurais e entre eles e os pesquisadores e técnicos.

Sua estrutura básica foi constituída por duas entidades fundamentais: a Fundação Agrária do Tocantins-Araguaia (FATA) e o Laboratório Sócio-Agronômico do Tocantins (LASAT), que se articularam, não sem conflitos, para pensar conjuntamente as diversas atividades que foram realizadas. No entanto, algumas atividades se realizaram sem a comunicação preconizada entre sindicalistas e pesquisadores, como, por exemplo, o Projeto Agro-Florestal (PAF) - o maior projeto do CAT em vários aspectos, que foi perpassado por meio de conflitos entre sindicalistas, pesquisadores do LASAT, a coordenação do CAT e financiadores estrangeiros. Outras entidades foram criadas no Programa à medida que avançaram as questões de comercialização - COCAT (Cooperativa Camponesa do Araguaia-Tocantins) - e de formação e escolarização de sindicalistas e jovens agricultores - EFA (Escola Família Agrícola).

Para pensar as ações conjuntamente, foi construída, em um sítio a 8 km de Marabá, uma estrutura física ou institucional, considerada por alguns atores regionais como "grande demais" para ser

30 Posteriormente mais dois municípios integraram o programa CAT: Nova Ipixuna, município que se emancipou de Itupiranga, foi integrado em 1996; São Domingos do Araguaia, município que se emancipou de São João do Araguaia foi integrado em 1993. A entrada desses dois municípios relaciona-se ao fato de serem áreas onde o Programa CAT já tinha atuação e que foram simplesmente desmembradas em novos municípios, não gerando, dessa forma, novas despesas para o Programa. 
apropriada pelos agricultores, contendo vários prédios e uma área experimental para a realização de atividades produtivas e de lazer. O Centro de Convivência da FATA (CECON) ou simplesmente CAT, como ficou mais conhecido, foi constituído de três salas de aula, o auditório (que, na maioria das vezes, serve como sala de aula), oito dormitórios para educandos, refeitório, cozinha, biblioteca, prédio administrativo, espaço de recreação com campo de futebol e quadra de areia.

Pela análise do material empírico também pude ressaltar que essa estrutura encontra-se hoje degradada, devido, em parte, à falta de recursos para a manutenção e conservação dos prédios, principalmente a partir de 2001, quando a FATA se integrou a FETAGRI regional. Atualmente, o movimento sindical entabula um debate com outras entidades da região, no sentido de resgatar o valor simbólico, material e político do Centro de Convivência da FATA, para além dos espaços de formação e escolarização que acontecem ali por meio da EFA.

Para efetivação das atividades, decidiu-se, desde o início, formar equipes permanentes de pesquisadores instalados na região, que trabalhariam em parceria contínua com as organizações sindicais. O fato de residir na região era condição imprescindível à integração e ao acompanhamento das ações de desenvolvimento. Quanto à duração, por tempo indeterminado, dos trabalhos da equipe, ela foi fundamentada na constatação de que uma intervenção de desenvolvimento sustentável só poderia ganhar consistência a médio e a longo prazo, sobretudo na escala considerada, bem como no interesse em integrar a formação superior como um dos componentes principais do projeto.

As equipes de pesquisa eram formadas por pesquisadores e técnicos nomeados, na sua maioria, por instituições ligadas ao projeto. Esses pesquisadores foram alocados no interior das áreas rurais, para a implementação da pesquisa. Os objetivos principais dessa pesquisa-ação foram negociados periodicamente e os temas eram debatidos em espaços como os Estágios de Base e Temáticos. Os pesquisadores consideraram implicitamente, no início dos trabalhos, que a aproximação entre a demanda dos sindicalistas e a oferta dos pesquisadores se faria progressivamente, graças à 
renegociação periódica das bases da pesquisa-ação, depois de avaliações conjuntas dos resultados e dos métodos empregados. Essa negociação periódica deveria também esclarecer, paulatinamente, as estratégias das instituições parceiras, de forma a identificar melhor os campos de cooperação, permitindo, assim, um benefício recíproco.

Os pesquisadores esperavam que esse tipo de metodologia permitisse reforçar as dinâmicas democráticas e a capacidade de os produtores influenciarem o desenvolvimento, elaborando, em parceria com os pesquisadores, o conhecimento da realidade, a busca de alternativas e a aplicação das soluções. A pesquisa participativa deveria atuar sobre os processos de transformação da sociedade de acordo com os produtores familiares. Isso condicionava o estabelecimento de uma verdadeira parceria com os produtores, baseada em respeito e confiança mútua, porém não sem conflitos e permeados por relações de poder.

A formação de pesquisadores e técnicos de nível superior foram outras atividades que tiveram grande visibilidade durante o Programa, principalmente no LASAT. Essas atividades tiveram início com o DAZ (Curso de Especialização em Agriculturas e Desenvolvimento Amazônico) em 1991 e se consolidaram com a criação do NEAF (Núcleos de Estudos Integrados sobre Agricultura Familiar), em 1994, dentro do Centro Agropecuário da UFPA. Posteriormente, foram criados cursos de graduação em Marabá e em Altamira, ajudando na disseminação da metodologia de pesquisa participativa preconizada pelo LASAT. Atualmente, este órgão mantém parcerias com outras organizações sociais (não só os sindicatos ligados à FATA) para elaborar temas de pesquisa.

As dificuldades entre pesquisadores e sindicalistas podem ser explicadas pelas diferenças que estes agentes e pela própria diversidade de formação, cultura, funções e interesses em jogo. Os sindicalistas, na maioria das vezes, identificaram- se com base em critérios políticos, pela defesa de uma categoria social ampla e definida a partir de critérios de classe social. Sua militância sindical foi definida em termos de alianças táticas, e procuram orientar os resultados de sua atividade de maneira a favorecer seus aliados 
e a desenvolver sua base, a partir das demandas que envolviam o fortalecimento econômico dos agricultores. Os pesquisadores, por sua vez, qualquer que seja seu engajamento político, para sobreviverem profissionalmente, deveriam obter reconhecimento no campo científico, o que supõe produtos científicos reconhecidos e, portanto, tipos de intervenção compatíveis com esse objetivo (GUERRA; CASTELLANET, 2005).

A existência de campos de interesse e de poder extremamente diferentes, de concepções de desenvolvimento e do papel do pesquisador igualmente diversos, tornou difícil a elaboração de uma aliança equilibrada, em que cada um se beneficia do outro sem ameaçá-lo (GUERRA; CASTELLANET, 2005). Pode-se concluir que a elaboração de uma estratégia conjunta entre dois grupos sociais muito diferentes requer muito mais do que o estabelecimento de um diálogo e do compartilhamento das regras do jogo.

Parece-me, entretanto, que foi possível chegar a um equilíbrio negociado nessa relação, a partir da identificação rigorosa de campos de interesses comuns bem definidos e, por contraste, de campos reservados, em que cada parceiro entende preservar sua supremacia e sua demanda, incitando o outro a minimizar sua interferência. Podem-se imaginar também as regras que permitiriam minimizar as zonas de fricção e de competição, e maximizar as áreas de cooperação e de interesse mútuo. 0 arranjo pressuporia uma negociação sobre o controle e a autolimitação tão caros aos pesquisadores, que não poderiam aceitar a renúncia a certos direitos, e de sua prática científica, em particular não aceitar não se imiscuir na política interna das organizações e respeitar a obrigação de confidencialidade em relação a certas informações consideradas estratégicas para as organizações de produtores (GUERRA; CASTELLANET, 2005).

Dessa forma, a coconstrução de novos conhecimentos, juntando o saber dos agricultores e conhecimento dos pesquisadores não foi uma tarefa simples, pois o relacionamento é uma construção social. Diálogo, parcerias, alianças não são instituídos a partir da definição de responsabilidades, direitos, deveres e regras do jogo bem redigidas no papel, e sim, são resultantes da forma como um percebe 
o outro e nas suas ações, atitudes, comportamento ao longo do cotidiano e do reconhecimento de alteridades (HÉBETTE, 1996b). Nessa perspectiva, a necessária oposição de saberes tornou-se a base de uma metodologia educacional de troca, em que os conhecimentos e práticas existentes se confrontavam e se transformavam em novos conhecimentos e práticas. Portanto, instrumentos que potencializavam a produção e possibilitavam um maior espaço de afirmação dos camponeses na cena política da região de Marabá, principalmente na segunda metade da década de 1990.

\section{A atuação do CAT na região de Marabá}

Dez anos depois do fim dessa experiência em 2001, resultados significativos para a região foram obtidos por ambas as partes. Porém, constatamos que o Programa CAT não pode servir de um elemento explicativo para todas as transformações que aconteceram na região de Marabá na década de 1990 e início do século XXI. Pois, nesta região, historicamente formada por processos sociais complexos e diversos, existiam outros atores presentes, como, por exemplo, a FASE, a CPT, o CEPASP e algumas ONGs atuando em várias frentes e com objetivos diversos. Nesse sentido, não dá para fazer uma separação clara entre o que foi resultado das atividades do Programa CAT e das outras entidades.

Mesmo com essa diversidade de agentes, alguns entrevistados enfatizaram que o Programa CAT contribuiu em vários aspectos para a região de Marabá. Por exemplo: o crescimento do número de associações e cooperativas, a capilaridade e legitimidade do movimento sindical nas delegacias sindicais, o aumento do debate sobre as políticas públicas para a agricultura e o acesso dos agricultores às políticas de crédito. No domínio da transformação, da industrialização e da comercialização dos produtos agrícolas, foram constituídas entidades, como cooperativa voltada para o desenvolvimento, no entanto, conservando uma perspectiva de luta sindical (COCAT). E no plano da assistência técnica, a COOPSERVIÇOS. No plano da formação e escolarização de jovens agricultores, a criação e consolidação da EFA, considerada pelos atores públicos regionais um dos passos mais significativos. Porém, o mais provável é que 
essas transformações na região pudessem ser resultado de outros processos que ocorriam paralelamente à atuação do CAT ou da combinação desses elementos.

Houve também muitos debates e alguns projetos realizados no âmbito da FATA, com o intuito de discutir com os agricultores um novo modelo de agricultura sustentável que fugisse do padrão de pecuarização que estava se dando de forma intensa no sudeste do Pará. Nesses espaços, tentava-se colocar para os agricultores a importância da diversificação da produção no lote e o investimento em outras culturas. Entretanto, a forte presença da pecuária permanecia como questão importante:

Na região de atuação, a principal cultura, se a gente entrar nos lotes, é o capim, é o pasto, é leite, é o gado. Então, por uma série de fatores, nós não conseguimos fazer com que aquela iniciativa dos plantios se transformasse de fato, se desenvolvesse para virar plantio dos agricultores, em pomares e tal (Entrevistado 03 - Sindicalista-Informação verbal).

Mesmo assim, alguns entrevistados consideraram que houve indicações de algumas mudanças positivas no sentido de pensar um novo padrão de alimentação para as famílias que participaram dos projetos na FATA e nas comunidades que foram atendidas, em torno de três mil famílias. Atualmente, existem também alguns agricultores que continuaram com plantações de frutíferas e deram continuidade às experiências de diversificação, mesmo depois de terem acabado os projetos de apoio.

As indicações dos entrevistados reafirmam alguns dados que foram discutidos por Solyno Sobrinho $(2004)^{31}$. Segundo esse autor,

31 Solyno Sobrinho teve uma participação essencial em um dos projetos do CAT. Em sua dissertação de Mestrado (SOLYNO SOBRINHO, 2004), analisou o ambiente institucional que orientou a exploração dos recursos na região de Marabá, particularmente no que diz respeito aos impulsos que deram suporte à pecuária bovina como atividade principal da economia rural da região, e seus efeitos nas unidades de produção familiar. Devido à importância e a abrangência de sua análise, 
apesar do significativo volume de recursos aplicados, nos últimos 20 anos, em projetos de apoio ao desenvolvimento e diversificação da agricultura familiar na região de Marabá (entre eles o Programa CAT), hoje, mais do que nunca, predomina a pecuária extensiva nos estabelecimentos familiares ${ }^{32}$.

Ele ainda comenta que, no final da década de 1990, a maioria dos consórcios de culturas permanentes que foram financiados, estava abandonada, remanescendo apenas aqueles que escaparam do fogo e os que estavam bem situados em relação ao mercado, razão pelo qual os agricultores passaram a dedicar-lhes uma maior atenção. Também influenciando a baixa performance na manutenção desses plantios, não prosperaram as iniciativas de beneficiamento e comercialização, que poderiam incentivar a manutenção e ampliação dos plantios com um melhor retorno dos agricultores.

De acordo com o autor, ocorreu uma rápida expansão da pecuária extensiva na década de 1990 na região de Marabá, "arrastando consigo a agricultura familiar para o absoluto domínio das pastagens, uma monocultura que inviabiliza outros possíveis usos da terra, e qualquer possibilidade de desenvolvimento sustentável baseado na diversidade" (Ibidem, p. 11).

De maneira semelhante, outras condições institucionais, em especial a política de crédito agrícola, estimularam a pecuária extensiva como opção preferencial de desenvolvimento da agricultura familiar na região de Marabá, condenando as experiências de desenvolvimento sustentável a "meros ensaios pontuais e isolados da realidade mais abrangente da região, com poucas chances de viabilidade econômica em um mercado que se organiza em escala somente para os produtos da pecuária" (Ibidem).

Nessa circunstância, o autor concluiu que seria:

Ingenuidade pensar que os simples experimentos pontuais estimulados pelo PPG7 na

utilizarei daqui para frente alguns elementos utilizados por ele para entender a atuação do Programa CAT na agricultura familiar dessa região.

32 Em que pese o uso de tecnologia muito elevada (como o uso de insumos), ela vem obtendo índices elevados de produtividade. 
década de 1990 em Marabá pudessem provocar uma revolução ambientalista na maneira de produzir dos camponeses. Quando se analisa o papel da pecuária na história econômica da região de Marabá, verifica-se que a atividade tem origens congênitas, inclusive na formação do campesinato na região, que ocupando áreas de difícil acesso, ou mesmo áreas já tomadas por pastagens no caso da ocupação de fazendas improdutivas, não vê outra opção melhor que a pecuária para alcançar certa estabilidade do padrão de reprodução da família (SOLYNO SOBRINHO, 2004, p.122).

Por outro lado, ele enfatizou que as soluções agroecológicas introduzidas na região pelos projetos de cunho ambientalista (o PAF, por exemplo), caracterizam-se pelo experimentalismo, razão pela qual não se mostraram tão replicáveis nas condições que se encontrava a região, principalmente pela fragilidade do mercado para produtos agroflorestais alternativos. Além disso, condicionados à exigência de um conhecimento ecológico local (que não se encontra entre os agricultores - a maioria formada de migrantes, vindos do Nordeste), e às restrições de cada tipo de estabelecimento, foram raros os exemplos de práticas agroecológicas que puderam se reproduzir em larga escala.

Numa outra perspectiva de análise, concluímos que os ganhos dos pesquisadores estavam mais relacionados aos bens que mais lhes agregam poder, que são os do tipo simbólico (reconhecimento acadêmico, divulgação de pesquisas) e, em certo sentido, recursos para a mobilização de pesquisas, fortalecendo também a instituição na qual representavam - visibilidade da UFPA tanto nacional quanto internacionalmente.

O trabalho iniciado com as organizações sindicais permitiu também aos pesquisadores uma penetração em diversos níveis das comunidades rurais, alcançando até os povoados mais distantes dos municípios. Essa proximidade permitiu constatar que a ação sindical, apesar de seu impacto real no campesinato, deixou 
a desejar no sentido de que existem agricultores que resistem ao engajamento social, em razão de posições políticas contraditórias com o discurso dessas entidades, ou de afinidades com outras forças não alinhadas a esse tipo de trabalho. Relações de clientelismo, paternalismo, distância geográfica ou outros interesses impediram a inserção completa da massa de agricultores no seio dessas organizações, que não escapam à regra e reproduziam frequentemente relações da mesma natureza.

Análises empíricas também me indicaram que era raro que verdadeiros debates tenham acontecido nas Assembleias Gerais da FATA $^{33}$. Tratava-se, em grande parte, de confirmar os acordos preparados antes, por contatos diretos ou negociações nos bastidores. Discussões sobre a representatividade dos sindicatos ou os modos de designação de seus responsáveis foram encarados como interferências inaceitáveis dos pesquisadores nas organizações sindicais, motivo por que foram cada vez menos convidados a participar das reuniões. Esse momento de maior conflito se deu a partir da consolidação da FETAGRI regional sudeste como o grande fórum articulador das políticas sindicais no final da década de 1990, contribuindo significativamente para a desestruturação do Programa CAT. Nesse sentido, os pesquisadores foram mantidos à distância do funcionamento das organizações sindicais, a fim de evitar qualquer risco de manipulação e de tomada de poder pelos intelectuais, bem como a interferência na gerência dos recursos disponibilizados, principalmente no âmbito da FATA.

Deve-se considerar que as características das relações analisadas nesse trabalho, desde uma perspectiva crítica, não eliminam a constatação de que todos esses agentes estiveram guiados por uma utopia, qual seja a construção de uma nova realidade social. Realidade esta que seja regida por valores de justiça, igualdade social entre os seres humanos numa região historicamente marcada pelo contexto da exploração e da violência. E é assim, mirando este ideal que os pesquisadores, sindicalistas, agricultores e assessores

33 Ocorria uma vez ao ano e reunia sindicalistas, pesquisadores e agricultores para tratar das decisões no âmbito da FATA. 
de diversas entidades lutaram por uma transformação política e social na região de Marabá.

Por este exercício, quero afinal destacar o papel da produção de ideias coletivas para influenciar a elaboração de outros ideários, pelos quais uma política pública passa a fazer sentido. Se o engajamento daqueles agentes na produção de outros sistemas de crenças de reordenação da vida social não alcançou moldar os programas emanados do Estado, essa avaliação não pode estar assim limitada. Daqueles agentes, muitos deram continuidade ao exercício de formação de novos profissionais para a prática intervencionista na agricultura, para a mobilização de agricultores segundo interesses mais contextuais. E os agricultores, adequando-se a referências de outros contextos, construíram outras instituições e encaminharam filhos para o ensino universitário de graduação e pós-graduação, boa parte deles hoje ocupando postos centrais na objetivação de outros ideários de sustentabilidade e responsabilidade social para a agricultura no Brasil e em Marabá. 


\section{Referências}

ASSIS, William Santos de. A construção da representação dos trabalhadores rurais do sudeste paraense. Rio de Janeiro: CPDA/UFRRJ. (Tese de Doutorado), 2007.

BOURDIEU, Pierre. O poder simbólico. Lisboa: Difel, 1989.

Razões práticas: sobre a teoria da ação. Campinas: Papirus, 1996.

. Contrafogos 2: por um movimento social europeu. Rio de Janeiro: Zahar, 2001.

HÉBETTE, Jean. O centro Agroambiental do Tocantins: propostas e desafios. Texto publicado in Proposta. Rio de Janeiro, XV (48), 32-37p, mar. 1991. In: HÉBETTE, J. Cruzando a fronteira: 30 anos de estudos do campesinato na Amazônia. Belém: EDUFPA, v. IV, 2004d.

- Reprodução social e participação política na fronteira agrícola paraense: o caso da Transamazônica. Texto apresentado no painel Movimentos Sociais Contemporâneos da BRASA Third Conference, em Cambridge, 07-10.09.1996a. In: . Cruzando a fronteira: 30 anos de estudos do campesinato na Amazônia. Belém: EDUFPA, v. IV., 2004d.

A relação pesquisadores-agricultores: diálogo, parceria, aliança? Uma análise estrutural. Texto apresentado no seminário Pesquisas para o desenvolvimento sustentável da agricultura familiar amazônica, promovido pelo NEAF em 1996b. In: Cruzando a fronteira: 30 anos de estudos do campesinato na Amazônia. Belém: EDUFPA, v. IV., 2004d.

Movimento sindical e ações de desenvolvimento rural: a construção de um nível regional de ação em parceria. Texto publicado no Seminário A construção local do território na Amazônia Oriental. 
Elementos para a construção de uma parceria entre organismos regionais em vista de um desenvolvimento, promovido pelo NEAF/UFPA, em Marabá, 19-21.03.1997. In: HÉBETTE, J. Cruzando a fronteira: 30 anos de estudos do campesinato na Amazônia. Belém: EDUFPA, v. IV., 2004 d.

HENCHEN, Mario José. o diálogo como relação entre agricultores e pesquisadores: a experiência do PAET na Transamazônica. (Dissertação de Mestrado), Programa de Mestrado em Sociologia: Universidade Federal do Pará, 2002.

GUERRA, G. A.D.; CASTELLANET, C. Pesquisadores engajados e líderes camponeses na pesquisa-ação: uma cooperação conflitante. Reflexões a partir dos programas CAT e Paet na Amazônia brasileira. Cadernos de Ciência \& Tecnologia, Brasília, v. 22, n. 2, p. 333-347, maio/ago. 2005.

LEROY, J.P. Da Fronteira sem lei nem direitos a uma democracia em construção: o campesinato da região de Marabá nos anos 80 e a criação do CAT. In: HÉBETTE, J.; NAVEGANTES, R. (orgs). CAT - Ano décimo: etnografia de uma utopia. Belém: UFPA: CAT, 2000.

MARTINS, José de Souza. Os Camponeses e a política no Brasil. Petrópolis: Vozes, 1995.

NEVES, D. P. Mediação social e mediadores políticos. In (Org). Desenvolvimento social e mediadores políticos. Porto Alegre: Editora da UFRGS: Programa de Pós-Graduação em Desenvolvimento Rural, 2008.

SOLYNO SOBRINHO, S. A. Constrangimento institucional para o desenvolvimento sustentável da agricultura familiar na região de Marabá. (Dissertação de Mestrado) NAEA: Universidade Federal do Pará, 2004. 
SOUZA, D. D. L. de. Organizações não-governamentais: um estudo de caso da Federação de Órgãos para a Assistência Social e Educacional (FASE). (Tese de Doutorado). Porto Alegre: UFRGS: Programa de PósGraduação em Educação, 2005.

TOURAINE, Alain. Crítica da modernidade. Rio de Janeiro: Vozes, 1984.

. Capitalismo autoritário e campesinato: um estudo comparativo a partir da fronteira em movimento. 2. ed. Rio de Janeiro: São Paulo: DIFEL, 1974.

WEBER, M. Economia e Sociedade: Fundamentos da sociologia compreensiva. 3. ed. Brasília: Editora da UNB, 1994. 